\title{
Gadolinium attenuates regional stunning in the canine heart in vivo
}

\author{
Alfred C. Nicolosi, MD \\ Gina West, BS ${ }^{a}$ \\ John G. Markley, MDa \\ Brent Logan, $\mathrm{PhD}^{\mathrm{b}}$ \\ Gordon N. Olinger, $M D^{\mathrm{a}}$
}

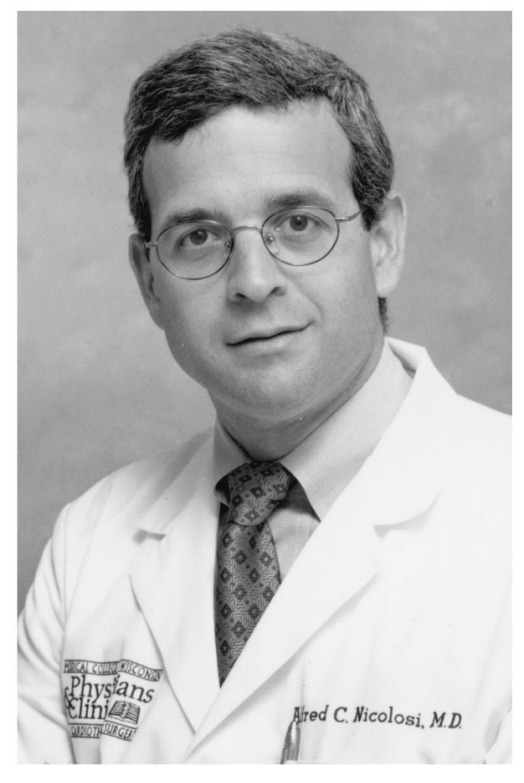

Dr Nicolosi
From the Divisions of Cardiothoracic Surgery $^{\mathrm{a}}$ and Biostatistics, ${ }^{\mathrm{b}}$ The Medical College of Wisconsin, Milwaukee, Wis.

Received for publication Sept 18, 2001; revisions requested Nov 19, 2001; revisions received Dec 27, 2001; accepted for publication Dec 28, 2001.

Address for reprints: Alfred C. Nicolosi, MD, Division of Cardiothoracic Surgery, Froedtert Memorial Lutheran Hospital, 9200 W Wisconsin Ave, Milwaukee, WI 53226 (E-mail: nicolosi@mcw.edu).

J Thorac Cardiovasc Surg 2002;124:57-62

Copyright (C) 2002 by The American Association for Thoracic Surgery

0022-5223/2002 $\$ 35.00+0 \quad \mathbf{1 2 / 1 / 1 2 2 5 2 4}$

doi:10.1067/mtc.2002.122524
Objective: Gadolinium, a lanthanide cation, ameliorates pathophysiologic features of both heart failure and cardiac arrhythmias. We have shown, in an in vitro model, that gadolinium blocks stretch-induced contractile dysfunction in both normal and stunned myocardium. The present study tested the hypothesis that gadolinium would also attenuate regional myocardial stunning in an in vivo model.

Methods: Mongrel dogs $(n=13)$ were subjected to regional myocardial ischemia (occlusion of the left anterior descending coronary artery) for 15 minutes, followed by reperfusion for 180 minutes. Intravenous gadolinium ( $500 \mu \mathrm{mol})$ was given to 7 dogs before ischemia; no gadolinium was given to control animals. Regional contractile function was assessed serially by means of both systolic shortening (percentage) and regional preload recruitable stroke work.

Results: Administration of gadolinium before ischemia had no effect on heart rate, arterial blood pressure, stroke volume, or regional contractile function. Ischemia resulted in paradoxical systolic bulging in both groups. After 180 minutes of reperfusion, systolic shortening was enhanced in gadolinium-treated animals compared with that in control animals $(10.9 \% \pm 1.5 \%$ vs $2.4 \% \pm 1.7 \%, P=.003)$. Both the slope and $\mathrm{x}$-axis intercept of regional preload recruitable stroke work returned to preischemic values in treated animals but remained abnormal in control animals.

Conclusions: These data confirm that gadolinium attenuates regional myocardial stunning in vivo. Gadolinium may cause peripheral vasodilatation but does not appear to exert positive inotropic effects on the normal canine heart. The mechanism underlying gadolinium-mediated effects on stunned myocardium remains undefined, but this study suggests that use of gadolinium may represent a novel adjunct to current cardioprotective strategies.

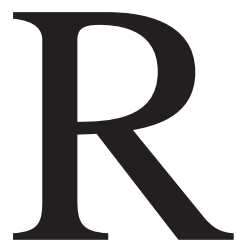

ecent reports indicate that gadolinium, a trivalent lanthanide cation, exerts a number of interesting effects on myocardial pathophysiology. Stretch-induced arrhythmias in both rabbit atria and canine ventricles are suppressed by gadolinium. ${ }^{1,2}$ Abnormal, swellinginduced ion currents that can be measured in cardiomyocytes from dogs with tachycardia-induced heart failure are also inhibited by gadolinium. ${ }^{3,4}$

Our laboratory has recently demonstrated, by using an isolated guinea pig papillary muscle model, that stretch-induced contractile dysfunction is attenuated by gadolinium both in normal myocardium and in myocardium that has been exposed to modified hypoxia-reoxygenation. ${ }^{5}$ On the basis of these observations in an in vitro model, we hypothesized that gadolinium would attenuate regional, postischemic contractile dysfunction (stunning) in vivo as well. Myocardial stunning is a 
complex, probably multifactorial process that remains incompletely understood. Observations made with an in vitro model with a crystalloid perfusate may not correlate with events that occur in association with ischemia and reperfusion in vivo because blood elements, particularly neutrophils, may play a key role in the pathophysiology. ${ }^{6}$ Regional stunning remains an important problem in cardiac operations, particularly in emergency procedures for acute coronary syndromes. Adjunctive therapies that can accelerate recovery of contractile function after reperfusion could have an obvious clinical effect. Accordingly, the present study tested the effects of intravenous gadolinium on serial measures of regional contractile function and hemodynamics in a canine model of in vivo myocardial stunning.

\section{Methods}

\section{Instrumentation}

Mongrel dogs $(\mathrm{n}=13$, approximately $25 \mathrm{~kg}$ ) were anesthetized with intravenous pentobarbital $(200 \mathrm{mg} / \mathrm{kg})$ and barbital $(26 \mathrm{mg} /$ $\mathrm{kg}$ ), intubated, and ventilated with supplemental oxygen. Normothermia was maintained with heating blankets. Catheters were placed into the femoral artery and vein. The heart was exposed by means of a left thoracotomy, and the left anterior descending coronary artery (LAD) was encircled with a silk thread immediately distal to the first diagonal branch. A micromanometer-tipped catheter (Millar Instruments, Inc, Houston, Tex) was inserted into the subclavian artery and was advanced retrograde across the aortic valve into the left ventricle. Two cylindrical ultrasonic dimension crystals (Triton Technology, Inc, San Diego, Calif) were imbedded into the midmyocardium $1 \mathrm{~cm}$ apart in the distal LAD territory and were connected to an ultrasonic dimension system (Crystal Biotech, Hopkinton, Mass). An ultrasonic flow probe (Transonics Systems, Inc, Ithaca, NY) was placed around the pulmonary artery and connected to a flowmeter (model T101, Transonics). The inferior vena cava was encircled with a reversible snare. Animals were stabilized for at least 15 minutes. Hematocrit and arterial blood gas levels were monitored throughout each experiment. Supplemental barbiturate anesthesia was given as indicated by corneal and hemodynamic reflexes.

\section{Protocol}

Heparin (100 U/kg) and lidocaine $(30 \mathrm{mg})$ were administered intravenously, and then baseline data were collected. Gadolinium (500 $\mu \mathrm{mol}$ administered intravenously) was then administered to one group of animals $(\mathrm{n}=7)$ in an unblinded fashion, and another data set was collected 5 minutes after injection in those animals. Gadolinium chloride hexahydrate (Aldrich Chemical, Milwaukee, Wis) was dissolved in $10 \mathrm{~mL}$ of $0.9 \% \mathrm{NaCl}$ solution and injected as a bolus. The LAD was then occluded in all animals by snaring the silk suture. In gadolinium-treated animals the interval between administration of gadolinium and the onset of ischemia was approximately 15 minutes. Additional lidocaine $(100 \mathrm{mg}$ ) was given to all animals as a continuous infusion during the occlusion. Ventricular fibrillation was treated as necessary with direct-current countershock. Data were collected after 10 minutes of ischemia. The coronary snare was released after 15 minutes, and the isch- emic segment was reperfused for 180 minutes. Final data were collected after 180 minutes.

All animals were killed at the end of the protocol by inducing ventricular fibrillation after achievement of deep general anesthesia. All animals received humane care in compliance with the "Principles of Laboratory Animal Care" formulated by the National Society for Animal research and the "Guide for the Care and Use of Laboratory Animals" prepared by the Institute of Laboratory Animal Resources, National Research Council, and published by the National Academy Press, revised 1996. This study was approved by the Medical College of Wisconsin Animal Care Committee.

\section{Data Analysis}

Hemodynamic and regional dimension data were collected at baseline, 5 minutes after injection of gadolinium (gadoliniumtreated animals), after 10 minutes of ischemia, and after 180 minutes of reperfusion. Data were digitized at $250 \mathrm{~Hz}$ per channel and stored directly to computer disk by means of commercial software (Codas, Akron, Ohio). Heart rate, mean arterial pressure, and stroke volume were measured in triplicate during a steady state and averaged. Right ventricular stroke volume was determined by integrating pulmonary artery flow on a beat-to-beat basis and was assumed to be equal to left ventricular stroke volume. The first derivative of left ventricular pressure with respect to time $(\mathrm{dP} / \mathrm{dt})$ was used to define events in the cardiac cycle.

Steady-state regional systolic shortening (in percentage) was derived from dimension data and was defined by the following formula:

$$
\mathrm{SS}=(\mathrm{EDL}-\mathrm{ESL}) / \mathrm{EDL}
$$

where SS is systolic shortening, EDL is end-diastolic length, and ESL is end-systolic length. End-diastole was defined as the point $40 \mathrm{~ms}$ before peak positive $\mathrm{dP} / \mathrm{dt}$, and end-systole was defined as the point $12 \mathrm{~ms}$ before peak negative $\mathrm{dP} / \mathrm{dt}$.

Instantaneous pressure-dimension relations were used to define regional preload recruitable stroke work (rPRSW) relations, as described by Glower and colleagues ${ }^{7}$ and as modified by the authors. ${ }^{8-10}$ Raw data were analyzed by means of commercial software (Mathcad 6.0 Standard Edition; Mathsoft Inc, Cambridge, Mass). In brief, a family of pressure-dimension loops was generated while preload was varied during transient inferior vena caval occlusion. Regional stroke work (SW; in millimeters of mercury per millimeter) was defined as follows:

$$
\mathrm{SW}=\int \mathrm{LVP} \times \Delta \mathrm{d}
$$

where left ventricular pressure (LVP) is integrated over the period from end-diastole to end-systole and $\Delta \mathrm{d}$ is defined as EDL minus ESL. Stroke work was then plotted on a beat-to-beat basis as a function of EDL and fitted to the following linear formula:

$$
\mathrm{SW}=\mathrm{M}_{\mathrm{w}}\left(\mathrm{EDL}-\mathrm{D}_{\mathrm{w}}\right)
$$

The slope of the rPRSW relation ( $\mathrm{M}_{\mathrm{w}}$; in millimeters of mercury) varies directly with contractile state in a load-independent fashion. The $\mathrm{x}$-axis intercept of $\mathrm{rPRSW}\left(\mathrm{D}_{\mathrm{W}}\right.$; in millimeters) represents the theoretical segment length in the completely unloaded state. We $\mathrm{W}^{10}$ have previously demonstrated that the value for $\mathrm{M}_{\mathrm{w}}$ may lose 
TABLE 1. Comparison of control animals $(n=6)$ at baseline with gadolinium animals $(n=7)$ before (baseline) and after administration of intravenous gadolinium (500 $\mu \mathrm{mol})$

\begin{tabular}{lccc}
\hline & $\begin{array}{c}\text { Control } \\
\text { baseline }\end{array}$ & $\begin{array}{c}\text { GAD } \\
\text { baseline }\end{array}$ & $\begin{array}{c}\text { GAD after } \\
\text { gadolinium }\end{array}$ \\
\hline HR (beats/min) & $118 \pm 8$ & $128 \pm 10$ & $124 \pm 12$ \\
MAP (mm Hg) & $114 \pm 8$ & $118 \pm 8$ & $110 \pm 9$ \\
SV (mL) & $21.4 \pm 2.6$ & $19.1 \pm 1.9$ & $20.6 \pm 1.7$ \\
Systolic shortening (\%) & $20.9 \pm 3.5$ & $15.5 \pm 1.8$ & $14.7 \pm 1.7$ \\
$M_{w}$ (mm Hg) & $20.1 \pm 5.2$ & $17.7 \pm 1.5$ & $17.6 \pm 3.4$ \\
$D_{w}(\mathrm{~mm})$ & $9.5 \pm 1.3$ & $9.4 \pm 0.7$ & $9.5 \pm 0.9$ \\
\hline
\end{tabular}

TABLE 2. Effects of regional myocardial ischemia and reperfusion on hemodynamics and rPRSW relations in control $(\mathbf{n}=$ 6) and gadolinium-treated $(n=7)$ dogs

\begin{tabular}{|c|c|c|c|c|c|c|}
\hline & \multicolumn{2}{|c|}{ Before ischemia } & \multicolumn{2}{|c|}{ Ischemia } & \multicolumn{2}{|c|}{ Reperfusion } \\
\hline & Control & GAD & Control & GAD & Control & GAD \\
\hline HR (beats/min) & $118 \pm 8$ & $128 \pm 10$ & $113 \pm 9$ & $123 \pm 12$ & $115 \pm 12$ & $123 \pm 12$ \\
\hline $\mathrm{MAP}(\mathrm{mm} \mathrm{Hg})$ & $114 \pm 8$ & $118 \pm 8$ & $107 \pm 8$ & $112 \pm 9$ & $117 \pm 10$ & $109 \pm 10$ \\
\hline SV $(\mathrm{mL})$ & $21.4 \pm 2.6$ & $19.1 \pm 1.9$ & $22.4 \pm 2.0$ & $19.0 \pm 1.6$ & $18.3 \pm 2.6$ & $18.8 \pm 2.1$ \\
\hline $\mathrm{M}_{\mathrm{w}}(\mathrm{mm} \mathrm{Hg})$ & $20.1 \pm 5.2$ & $17.7 \pm 1.5$ & NA & NA & NA & $16.1 \pm 4.0$ \\
\hline $\mathrm{D}_{\mathrm{w}}(\mathrm{mm})$ & $9.5 \pm 1.3$ & $9.4 \pm 0.7$ & $16.0 \pm 1.2^{*}$ & $14.6 \pm 1.2^{*}$ & $13.0 \pm 0.8^{*}$ & $9.3 \pm 1.0 \dagger$ \\
\hline
\end{tabular}

$H R$, Heart rate; $M A P$, mean arterial pressure; $S V$, stroke volume; $N A$, not applicable (see text for explanation).

${ }^{*} P<.01$ versus before ischemia.

$\dagger P=.012$ versus control.

correlation with contractile state during ischemia. In such circumstances $\mathrm{M}_{\mathrm{w}}$ often retains a positive value, although all values for SW during the inferior vena caval occlusion are negative because of ischemic systolic paradox. When this occurs, the value for $\mathrm{M}_{\mathrm{w}}$ is disregarded.

\section{Statistical Analysis}

Statistical consultation was obtained from the Division of Biostatistics of the Medical College of Wisconsin. Differences within the gadolinium-treated group from baseline to before ischemia were tested on each of 6 variables (Table 1) by means of a paireddifference $t$ test. A Bonferroni adjustment was used to control for multiple testing, and statistical significance was defined as a $P$ value of less than .05/6 (.0083) for these tests. The Wilcoxon signed-rank test was used to confirm these results and gave results consistent with those of the $t$ tests (data not shown).

Differences between groups were assessed by means of analysis of variance (ANOVA) for repeated measures before ischemia, during ischemia, and during reperfusion. Separate analyses were carried out for 3 hemodynamic variables (heart rate, mean arterial pressure, and stroke volume) and for the 2 indices of contractile function (systolic shortening and $\mathrm{D}_{\mathrm{w}}$ ) that could be measured at all 3 points in time. A Bonferroni adjustment was used to adjust the statistical significance level within each group of variables to control for multiple testing. In this manner statistical significance is defined as a $P$ value of less than $.05 / 3$ (.0167) for hemodynamic variables and a $P$ value of less than $.05 / 2(.025)$ for the indices of contractile function. Time-by-group interaction was used to test for different response profiles between the control and gadoliniumtreated groups. When this test result was significant, contrast tests were conducted to determine whether the return to preischemia values at reperfusion differed between groups. Because of the small sample size, a nonparametric analysis was performed to confirm the results of repeated-measures ANOVA. Analogous Wilcoxon rank sum tests were used to confirm all contrast test results. All nonparametric tests gave the same conclusions as repeated-measures ANOVA contrasts and are not presented here.

\section{Results}

Hemodynamics and regional contractile function in control animals at baseline and in gadolinium-treated animals both at baseline and after administration of gadolinium are summarized in Table 1. There were no baseline differences between control and gadolinium-treated animals with respect to any measured parameters. Administration of intravenous gadolinium was associated with a slight decrease in mean arterial pressure that was not significant after adjustment for multiple testing $(P=.012)$. Because gadolinium had no measured effects on normal cardiac function, baseline data were considered as the preischemic data for both groups in all further comparisons.

The effects of regional ischemia and reperfusion are summarized in Table 2 (hemodynamics and rPRSW relations) and Figure 1 (regional systolic shortening). Occlusion 


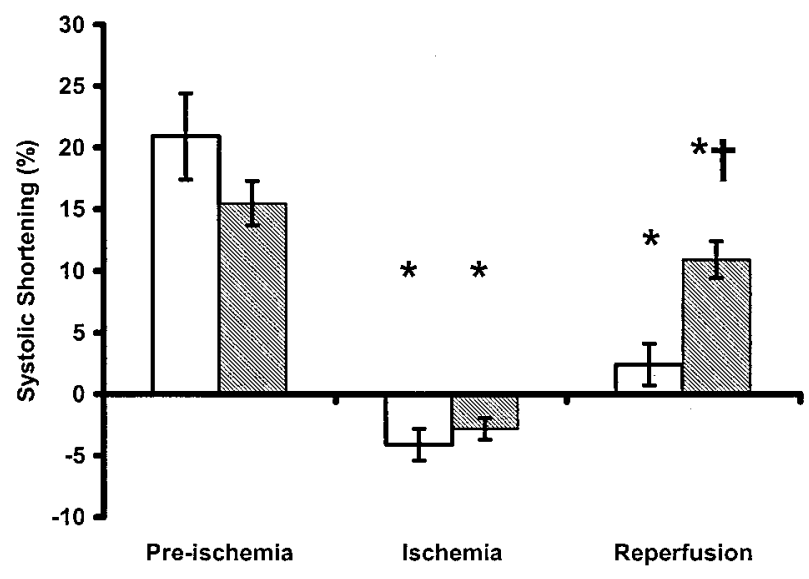

Figure 1. Mean \pm SEM systolic shortening in gadolinium-treated ( $n=7$; shaded bars) and untreated control ( $n=6$; open bars) dogs subjected to regional myocardial ischemia and reperfusion. Gadolinium was dissolved in $10 \mathrm{~mL}$ of saline solution and injected intravenously after collecting preischemic data. ${ }^{*} \boldsymbol{P}<.002$ versus preischemia; $\uparrow \boldsymbol{P}=.01$ versus control.

of the LAD did not alter hemodynamics but was associated with an expected decrease in regional systolic function that was characterized by paradoxical wall motion (negative systolic shortening in Figure 1) and was equal in both groups. The values obtained during ischemia for $\mathrm{M}_{\mathrm{w}}$ were disregarded in both groups because of the lack of physiologic correlation (see explanation in the "Methods" section) and are labeled as not applicable in Table 2. An ischemiainduced increase in $\mathrm{D}_{\mathrm{w}}$, indicating the development of diastolic creep, was observed in both groups $(P<.0001$ for both groups).

Systemic hemodynamics remained unchanged in both groups after 180 minutes of reperfusion. Regional systolic shortening, however, was enhanced in gadolinium-treated animals compared with in control animals $(10.9 \% \pm 1.6 \%$ vs $2.4 \% \pm 1.7 \%, P=.0014)$. The recovery of systolic shortening was thus $72 \% \pm 7 \%$ in gadolinium-treated animals and only $12 \% \pm 12 \%$ in controls. The $\mathrm{M}_{\mathrm{w}}$ demonstrated a persistent lack of physiologic correlation in control animals at 180 minutes of reperfusion but became valid again in gadolinium-treated animals, with a mean value that did not differ from the preischemia value. The $\mathrm{x}$-axis intercept of the rPRSW relation also returned to its preischemic value in gadolinium-treated animals, indicating the resolution of diastolic creep, but remained elevated in control animals $(P=.0096)$.

\section{Discussion}

The current study confirms our hypothesis that preischemic treatment with gadolinium attenuates contractile dysfunction after regional myocardial ischemia and reperfusion in vivo. Both systolic shortening and the $M_{w}$ were enhanced after 180 minutes of reperfusion in gadolinium-treated animals compared with that in untreated control animals. The differences in systolic shortening between control and gadolinium-treated groups at reperfusion (Figure 1) quantify the effects of gadolinium. The changes in $\mathrm{M}_{\mathrm{w}}$ (Table 2) provide qualitative proof of the effects of gadolinium on contractile function. Slope could not be evaluated in control animals during reperfusion because of the persistent lack of physiologic correlation in this index, yet gadolinium-treated animals exhibited normal rPRSW relations after 180 minutes of reperfusion. These results correlate with our previous in vitro study, in which gadolinium was observed to attenuate stretch-induced contractile dysfunction in both normal and stunned guinea pig papillary muscles. ${ }^{5}$ In addition, however, the present study demonstrates that ischemiainduced diastolic dysfunction, as defined by the $\mathrm{D}_{\mathrm{w}}$ is also reversed during reperfusion by gadolinium.

The underlying mechanism of gadolinium-related effects in the current study is not clear and may be multifactorial. Data from in vitro studies indicate that gadolinium acts as a nonselective antagonist of stretch-activated ion channels (SACs) in normal cardiac myocytes. ${ }^{11-13}$ The importance of SACs in cardiac disease has been implied by recent studies in which gadolinium alters the pathophysiology of both heart failure and arrhythmias. ${ }^{1-4}$ Although a role for SACs in postischemic contractile dysfunction (stunning) has not yet been established, regional myocardial ischemia is associated with abnormal tissue stretch, both in paradoxical systolic bulging and in diastolic creep. ${ }^{14,15}$ Isolated cardiomyocytes subjected to stretch exhibit increased intracellular diastolic calcium, ${ }^{16,17}$ which may be a central pathophysiologic mechanism of ischemia and reperfusion. ${ }^{18-21}$ Therefore, one may speculate that an SAC antagonist could block stretch-induced calcium entry into myocytes exposed to ischemia and reperfusion in vivo and thus attenuate contractile dysfunction.

$\mathrm{We}^{10}$ have previously reported that postischemic left ventricular decompression with a ventricular assist device (VAD) also enhances recovery of contractile function in the same canine model of regional stunning. It is tempting to speculate that the mechanism underlying these VAD-mediated effects also involves SACs. We demonstrated in that study that not only was abnormal segment stretch eliminated during full VAD flow, but both systolic and diastolic segment lengths were decreased well below normal preischemic lengths. The effects of the VAD on recovery of contractile function could not be related to any changes in regional myocardial blood flow. Perhaps closure of SACs during left ventricular decompression eliminates any contribution of ischemia-induced stretching to calcium overload. Further studies are needed to determine the relationship of SACs and the effects of mechanical circulatory support devices. 
Properties of gadolinium unrelated to SACs may also contribute to its observed effects on regionally stunned myocardium. In certain species and cell types, gadolinium exerts inhibitory effects on voltage-gated (ie, nonmechanogated) calcium channels, particularly L-type Ca channels. ${ }^{22,23}$ Effects on non-SAC channels may thus contribute to attenuation of calcium overload in postischemic cells. Gadolinium also exhibits certain anti-inflammatory properties that were recently described by Kono and colleagues ${ }^{24}$ to protect against endotoxin in hepatectomized rats. Cellular injury caused by local inflammation, with liberation of toxic oxygen free radicals, is thought to be another important pathophysiologic mechanism of ischemia and reperfusion. ${ }^{25-28}$ An anti-inflammatory effect might therefore be an important aspect of the gadolinium-mediated effects that were observed in the present study.

There was no evidence in the present study that gadolinium has any intrinsic inotropic properties in normal myocardium because both systolic shortening and rPRSW relations remained unchanged after intravenous administration of gadolinium. Gadolinium may exert a peripheral vasodilator effect in normal dogs, as indicated by the slight decrease in mean arterial pressure that occurred when gadolinium was administered in the baseline state. This effect, however, was not statistically significant and was not associated with changes in stroke volume or heart rate. Therefore, the effects of gadolinium on stunned myocardium cannot be understood on the basis of its effects on normal myocardium. In addition, we did not observe an increase in contractile force when normal guinea pig papillary muscles were exposed to gadolinium. ${ }^{5}$ The salutary effects of gadolinium on contractile function may be related to improved conduction of electrical impulses through stunned myocardium, reduced need for electrical defibrillation, or both. As noted above, gadolinium reduces myocardial vulnerability to stretch-induced arrhythmias. Unfortunately, however, we did not maintain an arrhythmia history during these experiments and are therefore unable to determine the role that anti-arrhythmic effects may have played in our results.

The effect of the present study on clinical practice remains speculative. Ischemia and reperfusion, however, remains an important problem in cardiac operations, particularly in the setting of acute coronary syndromes. Adjuncts that could accelerate recovery of contractile function in these patients would have obvious value. Gadolinium is currently used clinically only as a contrast agent in magnetic resonance imaging. The incidence of human toxicity of gadolinium when used as a contrast agent is extremely low $(<1 \%)$, and the majority of adverse reactions are allergic. Nonallergic reactions include nausea and headache. ${ }^{29,30}$ These preliminary data with gadolinium support a rationale to pursue further investigation into its mechanism or mechanisms of effect and possible applications. In particular, gadolinium-mediated effects must be preserved if it is administered during ischemia or on reperfusion to be useful clinically. These temporal relationships can be determined in future experiments.

In summary, pretreatment with gadolinium, an antagonist of SACs, accelerates recovery of contractile function after regional myocardial ischemia and reperfusion in dogs. Although the precise mechanism underlying this effect remains unknown, gadolinium may represent a novel adjunct in cardioprotective strategies.

We thank Mr Daniel Eastwood, Division of Biostatistics, for his assistance with manuscript preparation.

\section{References}

1. Bode F, Katchman A, Woosley RL, Franz MR. Gadolinium decreases stretch-induced vulnerability to atrial fibrillation. Circulation. 2000; 101:2200-05.

2. Hansen DE, Borganelli M, Stacy GP Jr, Taylor LK. Dose-dependent inhibition of stretch-induced arrhythmias by gadolinium in isolated canine ventricles. Evidence for a unique mode of antiarrhythmic action. Circ Res. 1991;69:820-31.

3. Clemo HF, Stambler BS, Baumgarten CM. Persistent activation of a swelling-activated cation current in ventricular myocytes from dogs with tachycardia-induced congestive heart failure. Circ Res. 1998;83: 147-57.

4. Clemo HF, Stambler BS, Baumgarten CM. Swelling-activated chloride current is persistently activated in ventricular myocytes from dogs with tachycardia-induced congestive heart failure. Circ Res. 1999;84: 157-65.

5. Nicolosi AC, Kwok CS, Contney SJ, Olinger GN, Bosnjak ZJ. Gadolinium prevents stretch-mediated contractile dysfunction in isolated papillary muscles. Am J Physiol Heart Circ Physiol. 2001;280: H1122-8.

6. Kloner RA, Bolli R, Marban E, Reinlib L, Braunwald E. Medical and cellular implications of stunning, hibernation and preconditiong. An NHLBI workshop. Circulation. 1998;97:1848-67.

7. Glower DD, Spratt JA, Snow ND, Kabas JS, Davis JW, Olsen CO, et al. Linearity of the Frank-Starling relationship in the intact heart: the concept of preload recruitable stroke work. Circulation. 1985;71:9941009.

8. Nicolosi AC, Weng Z-C, Detwiler PW, Spotnitz HM. Experimental left ventricular aneurysm and aneurysm repair in swine. J Thorac Cardiovasc Surg. 1990;100:745-55.

9. Markley JG, Nicolosi AC. Effects of left heart assist on geometry and function of the interventricular septum. Ann Thorac Surg. 1996;62: 1752-8.

10. Nicolosi AC, Markley JG, Olinger GN. Effects of post-ischemic left ventricular pressure-volume unloading on contractile recovery and myocardial blood flow in the regionally stunned canine heart. $J$ Thorac Cardiovasc Surg. 1999;118:181-8.

11. Hu H, Sachs F. Stretch-activated ion channels in the heart. J Mol Cell Cardiol. 1997;29:1511-23.

12. Kawakubo T, Naruse K, Matsubara T, Hotta N, Sokabe M. Characterization of a newly found stretch-activated $\mathrm{K}_{\mathrm{Ca} \text {,ATP }}$ channel in cultured chick ventricular myocytes. Am J Physiol Heart Circ Physiol. 1999;276:H1827-38.

13. Zeng T, Bett GCL, Sachs F. Stretch-activated whole cell currents in adult rat cardiac myocytes. Am J Physiol Heart Circ Physiol. 2000; 278:H548-57.

14. Tennant R, Wiggers CJ. The effect of coronary occlusion on myocardial contraction. Am J Physiol. 1935;112:351-61.

15. Edwards CH, Rankin JS, McHale P, Ling D, Anderson RW. Effects of ischemia on left ventricular regional function in the conscious dog. Am J Physiol Heart Circ Physiol. 1981;240:H413-20. 
16. Le Guennec J-Y, White E, Gannier F, Argibay JA, Garnier D. Stretchinduced increase of resting intracellular calcium concentration in single guinea-pig ventricular myocytes. Exp Physiol. 1991;76:975-8.

17. Todaka K, Ogino K, Gu A, Burkhoff D. Effect of ventricular stretch on contractile strength, calcium transient, and cAMP in intact canine hearts. Am J Physiol Heart Circ Physiol. 1998;274:H990-1000.

18. Gao WD, Atar D, Backx PH, Marban E. Relationship between intracellular calcium and contractile force in stunned myocardium. Circ Res. 1995;76:1036-48.

19. Gao WD, Liu Y, Mellgren R, Marban E. Intrinsic myofilament alterations underlying the decreased contractility of stunned myocardium. Circ Res. 1996;78:455-65.

20. Meissner A, Morgan JP. Contractile dysfunction and abnormal $\mathrm{Ca} 2+$ modulation during postischemic reperfusion in rat heart. Am J Physiol Heart Circ Physiol. 1995;268:H100-11.

21. Steenbergen C, Murphy E, Levy L, London RE. Elevation in cytosolic free calcium concentration early in myocardial ischemia in perfused rat heart. Circ Res. 1987;60:700-7.

22. Lacampagne A, Gannier F, Argibay J, Garnier D, Le Guennec J-Y. The stretch-activated ion channel blocker gadolinium also blocks 1-type calcium channels in isolated ventricular myocytes of the guinea pig. Biochim Biophys Acta. 1994;1191:205-8.

23. Caldwell RA, Clemo HF, Baumgarten CV. Using gadolinium to identify stretch-activated channels: technical considerations. Am J Physiol Cell Physiol. 1998;275:C619-21.
24. Kono H, Fujii H, Matsuda M, Yamamoto M, Matsumoto Y. Gadolinium chloride prevents mortality in hepatectomized rates given endotoxin. J Surg Res. 2000;96:204-10.

25. Bolli R, Jeroudi MO, Patel BS, DuBose CM, Lai EK, Roberts R, et al. Direct evidence that oxygen-derived free radicals contribute to postischemic myocardial dysfunction in the intact dog. Proc Natl Acad Sci U S A. 1989;86:4695-9.

26. Jeroudi MO, Triana FJ, Patel BS, Bolli R. Effect of superoxide dismutase and catalase, given separately, on myocardial "stunning." Am J Physiol Heart Circ Physiol. 1990;259:H889-901.

27. Sekeli S, McCay PB, Li X-Y, Zughaib M, Sun TZ, Tang X-L, et al. Direct evidence that the hydroxyl radical plays a pathogenetic role in myocardial "stunning" in the conscious dog and that stunning can be markedly attenuated without subsequent adverse effects. Circ Res. 1993; 73:705-23.

28. Bolli R. Role of neutrophils in myocardial stunning after brief ischaemia: the end of a six-year-old controversy (1987-1993). Cardiovasc Res. 1993;27:728-30

29. Cochran ST, Bomyea K, Sayre JW. Trends in adverse events after IV administration of contrast media. Am J Radiol. 2001;176:1385-8.

30. Murphy KP, Szopinski KT, Mermillod B, Ellis JH. Occurrence of adverse reactions to gadolinium-based contrast material and management of patients at increased risk: a survey of the American Society of Neuroradiology Fellowship Directors. Acad Radiol. 1999; 6:656-64.

Access to The Journal of Thoracic and Cardiovascular Surgery Online is reserved for print subscribers!

Full-text access to The Journal of Thoracic and Cardiovascular Surgery Online is available for all print subscribers. To activate your individual online subscription, please visit The Journal of Thoracic and Cardiovascular Surgery Online, point your browser to http://www.mosby.com/jtcvs, follow the prompts to activate your online access, and follow the instructions. To activate your account, you will need your subscriber account number, which you can find on your mailing label (note: the number of digits in your subscriber account number varies from 6 to 10). See the example below in which the subscriber account number has been circled:

\section{Sample mailing label}

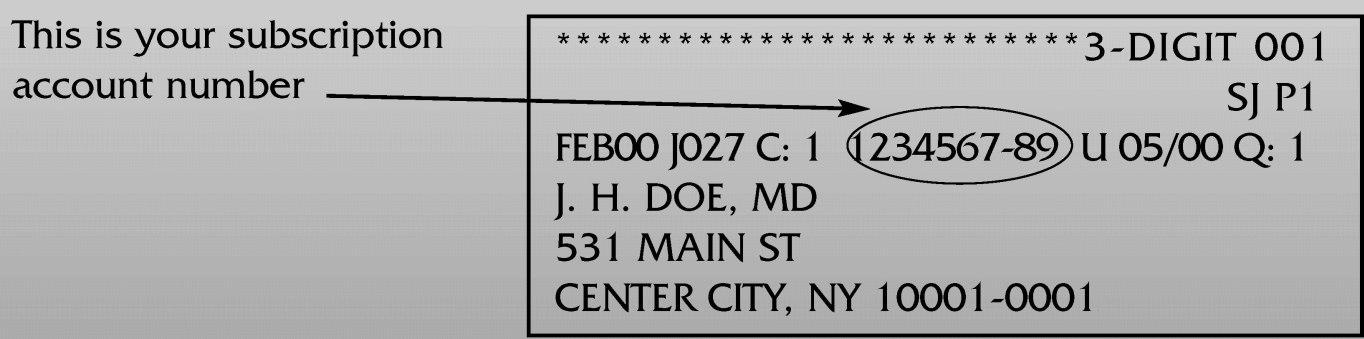

Personal subscriptions to The Journal of Thoracic and Cardiovascular Surgery Online are for individual use only and may not be transferred. Use of The Journal of Thoracic and Cardiovascular Surgery Online is subject to agreement to the terms and conditions as indicated online. 